\title{
Analisa Pipa Heat Exchanger (Cooling Tube) Bervariasi Pada Turbine Guide Bearing Pembangkit Listrik Tenaga Air Siguragura
}

\author{
Tambos August Sianturi
}

Dosen Prodi Teknik Mesin, Universitas HKBP Nommensen Pematangsiantar

Jln. Sangnawaluh Pematang Siantar

\begin{abstract}
A heat exchanger is a medium used to produce heat transfer from one fluid to another. Heat Exchanger can be used to raise the temperature or as a heater (regenerator) or lower the temperature or as a coolant (recuperator) depending on the view of heat transfer that occurs. Heat exchangers have been widely used in industries such as the chemical industry, paper industry, power plants, and other industries. In the example, each machine unit uses a heat exchanger media (especially rotary type machines) to keep the bearing temperature in normal temperature even though the unit is operated continuously or continuously. This study will analyze the temperature drop that occurs when the length of the heat exchanger pipe is added to the turbine guide bearing of PLTA Siguragura. From the research results, the maximum temperature on the guide bearing cooling tube reaches $\left.47.3{ }^{\circ} \mathrm{C}\right]$, the overall heat transfer coefficient on the guide bearing cooling tube is $98.87\left[\mathrm{~W} / \mathrm{m}^{2 \circ} \mathrm{C}\right], \Delta \mathrm{Tmin}$ on the guide bearing cooling tube installed (with 2 layers) is $\left.14.1{ }^{\circ}{ }^{\circ} \mathrm{C}\right]$ and $\Delta \mathrm{Tmin}$ which can be achieved with a cross-sectional area of $5.73\left[\mathrm{~m}^{2}\right]$ is $6.63\left[{ }^{\circ} \mathrm{C}\right]$.
\end{abstract}

Keywords: heat exchangers, guide bearings, power generators

\section{PENDAHULUAN}

Sistem pemeliharaan (maintenance) rutin dilakukan terhadap turbin PLTA Siguragura guna menjaga kehandalan (perfomance), daya tahan (lifetime), dan fungsi sesuai dengan kebutuhan. Sistem pemeliharaan (maintenance) juga sangat penting dilakukan guna menjaga terjadinya kerusakan sehingga tidak dapat digunakan (function failure). Salah satu komponen pada PLTA yang rutin dilakukan kegiatan pemeliharaan (maintenance) adalah Guide Bearing Cooling Tube.

Dalam menjaga posisi turbine shaft yang berputar dengan kecepatan mencapai 333 rpm, digunakan guide bearing yang berfungsi untukmenjaga agar turbine shaft tetap berada dalam satu poros (center). Pada saat pengoperasian, guide bearing terkena gaya gesek akibat rotasi turbine shaft menyebabkan temperatur mengalami kenaikan. Untuk menjaga agar guide bearing tetap dalam temperatur yang normal, guide bearing diberikan pelumasan menggunakan oli, dengan kondisi guide bearing direndam didalam oli secara terus menerus dalam proses operasi. Untuk menurunkan temperatur oli yang meningkat dikarenakan terjadi perpindahan panas pada guide bearing, didalam oil dam atau tangki oli dialiri air yang bersirkulasi terus menerus melalui pipa yang disebut dengan Cooling Tube. Oli yang digunakan pada proses heat exchanger tersebut adalah Pertamina TURBOLUBE XT-46, pada kondisi dilapangan temperatur oli dijaga dengan standar maksimum $60^{\circ} \mathrm{C}$.

\section{METODOLOGI PENELITIAN}

\section{2,1, Pengambilan Data}

2.1.1. Siklus Heat Exchanger pada turbin PLTA Siguragura 
Berdasarkan siklus heat exchanger pada turbin PLTA Siguragura, siklus alat penukar kalor (heat exchanger)pada pembangkit listrik tenaga air Siguragura (PLTA Siguragura) dapat digambarkan sebagai berikut :

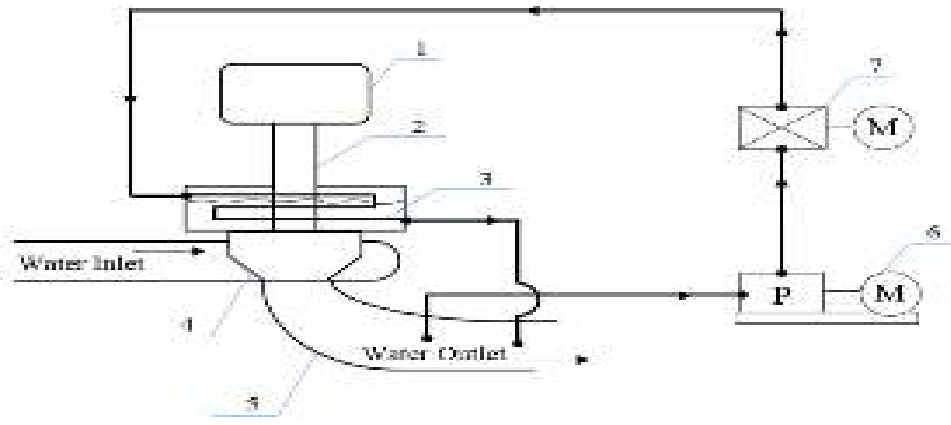

Gambar 1. Siklus heat exchanger pada turbin PLTA Siguragura

Keterangan :

1. Rotor

2. Turbine Shaft

3. Turbine Guide Bearing Cooling Tube

4. Runner
5. Draftube

6. Main Water Supply Pump

7. Main Water Strainer

\subsubsection{Desain guide bearing cooling tube}

Guide bearing cooling tube merupakan komponen yang direncanakan akan dimodifikasi. Hasil pengukuran pada komponen tersebut, guide bearing cooling tube memiliki bentuk seperti berikut :

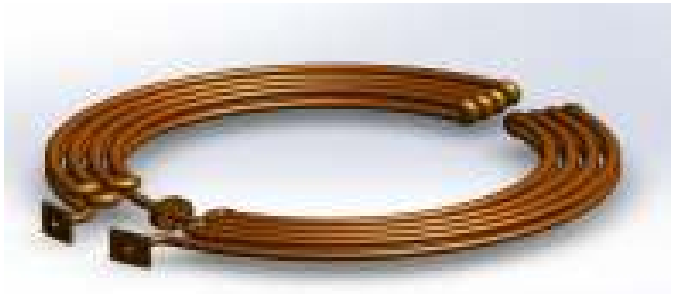

Gambar 2. Guide bearing cooling tube

Guide bearing cooling tube yang memiliki fungsi sebagai pipa penyalur air yang digunakan untuk proses perpindahan panas (heat transfer) antara air yang berada dalam tube dan oli yang berada pada oil dam.

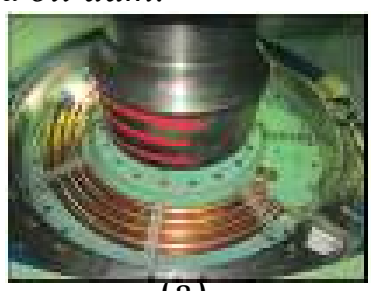

(a)

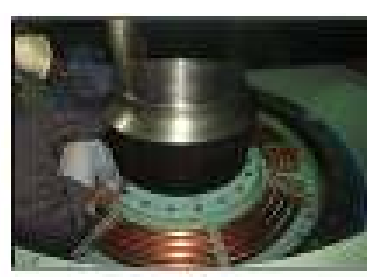

(b)

Gambar 3. (a) Proses pemasangan, (b) pengukuran dimensi guide bearing cooling tube

Dari hasil pengukuran pada saat pemasangan guide bearing cooling tube dilapangan, didapatkan dimensi dapat dilihat pada tabel Dimensi Layer Guide Bearing Cooling Tube 
Tabel 1. Dimensi Layer Guide Bearing Cooling Tube

\begin{tabular}{|l|c|c|}
\hline \multicolumn{3}{|c|}{ Upper Layer Guide Bearing Cooling Tube } \\
\hline \multicolumn{1}{|c|}{ Item Pengukuran } & $\begin{array}{c}\text { Dimensi Jari-jari } \\
{[\mathrm{mm}]}\end{array}$ & $\begin{array}{c}\text { Sudut Keliling } \\
{\left[{ }^{\circ}\right]}\end{array}$ \\
\hline Jari-jari 1 (R1) & $620[\mathrm{~mm}]$ & $302\left[^{\circ}\right]$ \\
\hline Jari-jari 2 (R2) & $680[\mathrm{~mm}]$ & $302\left[^{\circ}\right]$ \\
\hline Jari-jari 3 (R3) & $740[\mathrm{~mm}]$ & $302\left[^{\circ}\right]$ \\
\hline Jari-jari 4 (R4) & $800[\mathrm{~mm}]$ & $302\left[^{\circ}\right]$ \\
\hline Jari-jari 1 (R1') & $620[\mathrm{~mm}]$ & $340\left[^{\circ}\right]$ \\
\hline Jari-jari 2 (R2') & $680[\mathrm{~mm}]$ & $302\left[^{\circ}\right]$ \\
\hline Jari-jari 3 (R3') & $740[\mathrm{~mm}]$ & $302\left[^{\circ}\right]$ \\
\hline Jari-jari 4 (R4') & $800[\mathrm{~mm}]$ & $322\left[^{\circ}\right]$ \\
\hline
\end{tabular}

$K=2 . \pi \cdot r \cdot \frac{x}{360^{\circ}} \quad$ (Naniek A. Agus, Mudah Belajar Matematika, P.19)

Keterangan:

$K=$ Keliling $[\mathrm{mm}]$

$\pi=$ koefisien $p h i=3.14159$

$r=$ Jari - jari [mm]

$x=$ sudut bentangan $\left[{ }^{\circ}\right]$

Panjang bentangan:

$$
\begin{gathered}
K=\left(2 \cdot \pi \cdot r_{1} \cdot \frac{x_{1}{ }^{\prime}}{360^{\circ}}\right)+\left(2 \cdot \pi \cdot r_{2} \cdot \frac{x_{2}{ }^{\prime}}{360^{\circ}}+\left(2 \cdot \pi \cdot r_{3} \cdot \frac{x_{3}{ }^{\prime}}{360^{\circ}}\right)+\left(2 \cdot \pi \cdot r_{4} \cdot \frac{x_{4}{ }^{\prime}}{360^{\circ}}\right)+\left(2 \cdot \pi \cdot r_{1}{ }^{\prime} \cdot \frac{x_{1}{ }^{\prime}}{360^{\circ}}\right)\right. \\
+\left(2 \cdot \pi \cdot r_{2}{ }^{\prime} \cdot \frac{x_{2}{ }^{\prime}}{360^{\circ}}\right)+\left(2 \cdot \pi \cdot r_{3}{ }^{\prime} \cdot \frac{x_{3}{ }^{\prime}}{360^{\circ}}\right)+\left(2 \cdot \pi \cdot r_{4}{ }^{\prime} \cdot \frac{x_{4}{ }^{\prime}}{360^{\circ}}\right)
\end{gathered}
$$

\subsubsection{DATA TEMPERATUR GUIDE BEARING COOLING TUBE}

Berdasarkan hasil pengambilan data temperatur air dan oli guide bearingcooling tube dapat kita lihat pada tabel

Tabel 2. Temperatur air dan oli pada PLTA Siguragura Unit No. 2

\begin{tabular}{|c|l|r|}
\hline Item & \multicolumn{1}{|c|}{ Description } & Temperature \\
\hline $\begin{array}{c}\text { Guide Bearing } \\
\text { Cooling Tube }\end{array}$ & W/T G. Metal (Inlet) $\left(T_{1}\right)$ & $47.3\left[{ }^{\circ} \mathrm{C}\right]$ \\
\cline { 2 - 3 } & W/T G. Oil (Outlet) $\left(T_{2}\right)$ & $41.6\left[{ }^{\circ} \mathrm{C}\right]$ \\
\hline $\begin{array}{c}\text { Cooling Water } \\
\text { System }\end{array}$ & Inlet $\left(T_{3}\right)$ & $25.0\left[{ }^{\circ} \mathrm{C}\right]$ \\
\cline { 2 - 3 } & Outlet $\left(T_{4}\right)$ & $27.5\left[{ }^{\circ} \mathrm{C}\right]$ \\
\hline $\begin{array}{c}\text { Ambient } \\
\text { Temperatur }\end{array}$ & Turbine Pit & $28.0\left[{ }^{\circ} \mathrm{C}\right]$ \\
\cline { 2 - 3 } & Generator Room & $27.5\left[{ }^{\circ} \mathrm{C}\right]$ \\
\hline
\end{tabular}

Profil temperature heat exchanger guide bearing cooling tube dapat digambarkan sebagai berikut: 


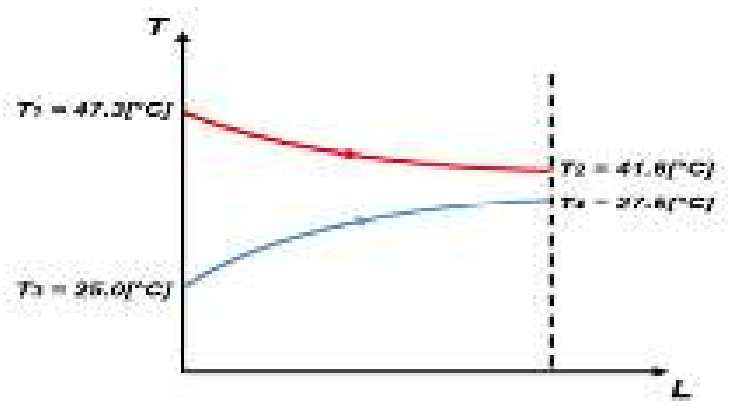

Gambar 4. Profil temperatur aliran sejajar pada guide bearing cooling tube

Dari hasil pengambilan data temperatur air dan oli guide bearing cooling tube, didapatkan profil temperatur yang digunakan untuk melakukan perhitungan perbedaan temperatur rata-rata logaritma (LMTD)dengan hasil perhitungan sebagai berikut:

$$
L M T D=\frac{\Delta T_{\max }-\Delta T_{\min }}{\ln \left(\frac{\Delta T \max }{\Delta T \min }\right)} \quad \text { (RogerKinsky, Heat Engineering, }
$$

Keterangan:

$\Delta T_{\max }=$ Perbedaan temperatur maksimal $/$ tertinggi $\left[{ }^{\circ} \mathrm{C}\right]$

$\Delta T_{\min }=$ Perbedaan temperatur minimal $/$ terendah $\left[{ }^{\circ} \mathrm{C}\right]$

Perbedaan temperatur rata-rata logaritma (LMTD):

$$
L M T D=\frac{(47.3-25.0)\left[{ }^{\circ} \mathrm{C}\right]-(41.6-27.5)\left[{ }^{\circ} \mathrm{C}\right]}{\ln \left(\frac{(47.3-25.0)\left[{ }^{\circ} \mathrm{C}\right]}{(41.6-27.5)\left[{ }^{\circ} \mathrm{C}\right]}\right)}=17.8898\left[{ }^{\circ} \mathrm{C}\right]
$$

\subsubsection{Koefisien perpindahan kalor menyeluruh guide bearing cooling tube}

Koefisien perpindahan kalor total turbine guide bearing cooling tube didapatkan melalui hasil perhitungan dari koefisien konvektivitas dan koefisien konduktivitas. Dimana pada tabel didapatkan data dan perhitungannya dapat dilakukan seperti berikut:

Tabel 3. Nilai massa jenis dan koefisien pindah panas konveksi dari bahan cair

\begin{tabular}{|l|l|l|}
\hline Jenis Zat & $\boldsymbol{\rho}$ Bahan $\left[\mathbf{k g} / \mathbf{m}^{3}\right]$ & $\boldsymbol{h}$ Bahan \\
\hline Air & 990 & 203.54 \\
\hline Garam & 0.4 & 155.98 \\
\hline Oli Pelumas & 543 & 192.34 \\
\hline Rumput Laut & 962.15 & 128.59 \\
\hline
\end{tabular}

$\frac{1}{U}=\frac{1}{h_{i}}+\Sigma \frac{x}{k}+\frac{1}{h_{o}} \quad$ (Roger Kinsky, Heat Engineering, $)$

Keterangan:

$U=$ Keofisien perpindahan kalor menyeluruh $\left[\mathrm{W} / \mathrm{m}^{2}{ }^{\circ} \mathrm{C}\right]$

$h_{i}=$ Koefisien konveksi air $\left[\mathrm{W} / \mathrm{m}^{2}{ }^{\circ} \mathrm{C}\right]$

$x=$ Tebal material $[\mathrm{m}]$

$k=$ Konduktivitas termal material $\left[\mathrm{W} / \mathrm{m}^{\circ} \mathrm{C}\right]$

$h_{o}=$ Koefisien konveksi oli $\left[\mathrm{W} / \mathrm{m}^{2 \circ} \mathrm{C}\right]$

Koefisien perpindahan kalor menyeluruh :

$$
\frac{1}{U}=\frac{1}{203.54\left[\mathrm{~W} / \mathrm{m}^{2}{ }^{\circ} \mathrm{C}\right]}+\frac{0.0008[\mathrm{~m}]}{385\left[\mathrm{~W} / \mathrm{m}^{\circ} \mathrm{C}\right]}+\frac{1}{192.34\left[\mathrm{~W} / \mathrm{m}^{2}{ }^{\circ} \mathrm{C}\right]}
$$




$$
U=98.87\left[\mathrm{~W} / \mathrm{m}^{2}{ }^{\circ} \mathrm{C}\right]
$$

\subsubsection{Laju perpindahan kalor guide bearing cooling tube}

Laju perpindahan kalor dapat ditentukan setelah luas penampang, LMTD, dan koefisien menyeluruh sudah dtentukan, maka:

$$
\mathrm{Q}=\mathrm{U} \text {. A . LMTD （RogerKinsky, Heat Engineering) }
$$

Keterangan :

$\mathrm{Q}=$ Laju perpindahan kalor $[\mathrm{W}] \quad \mathrm{A}=$ Luas penampang $\left[\mathrm{m}^{2}\right]$

$\mathrm{U}=$ Keofisien perpindahan kalor menyeluruh $\left[\mathrm{W} / \mathrm{m}^{2}{ }^{\circ} \mathrm{C}\right]$

$\mathrm{LMTD}=$ Perbedaan temperatur rata-rata logaritma $\left[{ }^{\circ} \mathrm{C}\right]$

Sehingga,

$$
\begin{aligned}
& \mathrm{Q}=98.87\left[\mathrm{~W} / \mathrm{m}^{2}{ }^{\circ} \mathrm{C}\right] .3 .85\left[\mathrm{~m}^{\wedge} 2\right] .17 .89\left[{ }^{\circ} \mathrm{C}\right] \\
& \mathrm{Q}=6,809.03[\mathrm{~W}]
\end{aligned}
$$

Data laju perpindahan panas dapat digunakan untuk menentukan laju aliran massa fluida melalui persamaan berikut:

$$
Q=\dot{\mathrm{m}} \cdot C_{p} \cdot\left(T_{h, \text { in }}-T_{h, \text { out }}\right) \quad \text { (Ali H. Pane, Alat Penukar Kalor, }
$$

Dari hasil perhitungan perbedaan laju perpindahan kalor pada guide bearing cooling tubedidapatkan nilai sebesar 6,809.03[W] dengan laju aliran massa sebesar 0.65 [kg/s].

\subsection{Diagram Alir Penelitian}

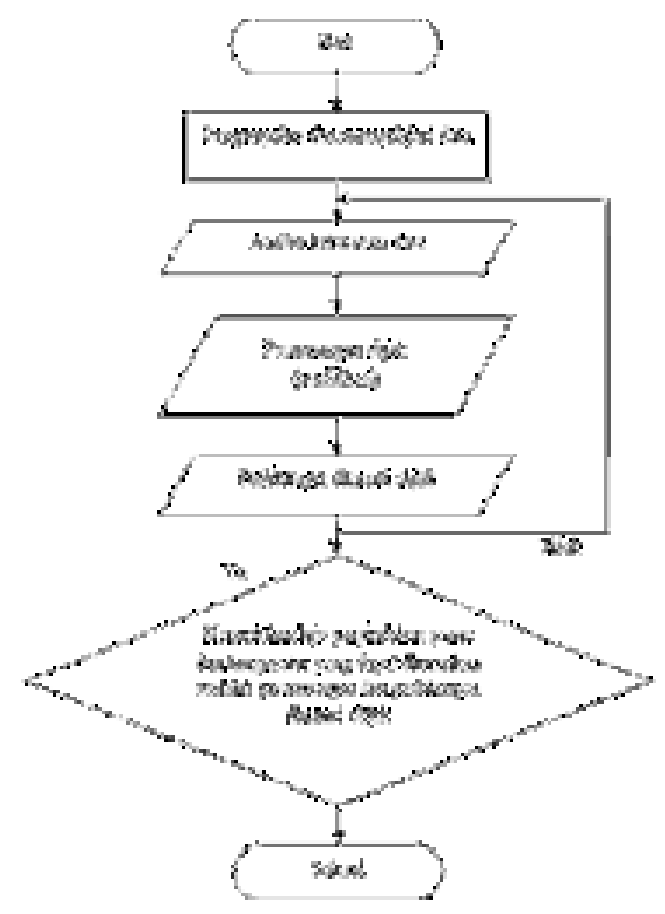

Gambar 5. Diagram alir metodologi penelitian

\section{HASIL DAN PEMBAHASAN}

\subsection{Analisa Guide Bearing Cooling Tube 1 Layer}

Guide bearing cooling tube merupakan komponen yang direncanakan akan dimodifikasi dari desain awal. Pada desain yang direncanakan, cooling tube akan 
dianalisa menjadi satu layer saja, dengan bentuk rancangan cooling tube sebagai berikut:

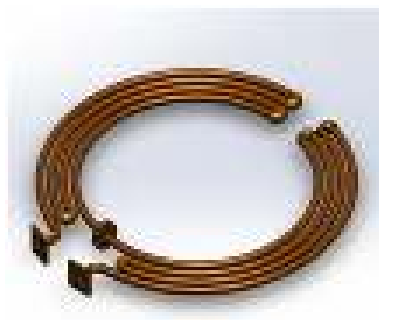

Gambar 6. Guide bearing cooling tube 1 layer

Dari hasil perhitungan pada rencana perancangan cooling tube yang dimodifikasi, didapatkan dimensi yang digunakan untuk perhitungan luas penampang yang merupakan permukaan area kontak (surface area)luas perhitungan sebagai berikut:

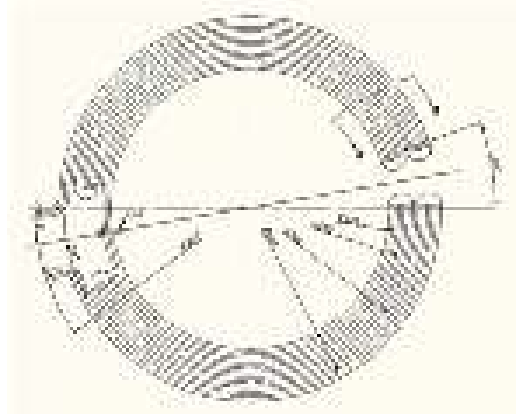

Gambar 7. Detail drawing Turbine Guide Bearing Cooling Tube 1 layer

Tabel 4. Dimensi 1 Layer Guide Bearing Cooling Tube

\begin{tabular}{|l|c|c|}
\hline \multicolumn{3}{|c|}{ Lower Layer Guide Bearing Cooling Tube } \\
\hline \multicolumn{1}{|c|}{ Item Pengukuran } & $\begin{array}{c}\text { Dimensi Jari-jari } \\
{[\mathrm{mm}]}\end{array}$ & $\begin{array}{c}\text { Sudut Keliling } \\
{\left[{ }^{\circ}\right]}\end{array}$ \\
\hline Jari-jari 1 (R1) & $620[\mathrm{~mm}]$ & $340\left[{ }^{\circ}\right]$ \\
\hline Jari-jari 2 (R2) & $680[\mathrm{~mm}]$ & $302\left[^{\circ}\right]$ \\
\hline Jari-jari 3 (R3) & $740[\mathrm{~mm}]$ & $302\left[^{\circ}\right]$ \\
\hline Jari-jari 4 (R4) & $800[\mathrm{~mm}]$ & $322\left[^{\circ}\right]$ \\
\hline
\end{tabular}

$$
K=2 \cdot \pi \cdot r \cdot \frac{x}{360^{\circ}}
$$

Panjang bentangan guide bearing cooling tube,:

$$
\begin{aligned}
& K=\left(2 . \pi \cdot r_{1} \cdot \frac{x_{1^{\prime}}}{360^{\circ}}\right)+\left(2 . \pi \cdot r_{2} \cdot \frac{x_{2^{\prime}}}{360^{\circ}}\right)+\left(2 . \pi \cdot r_{3} \cdot \frac{x_{3}{ }^{\prime}}{360^{\circ}}\right)+\left(2 . \pi \cdot r_{4} \cdot \frac{x_{4}{ }^{\prime}}{360^{\circ}}\right) \\
& \begin{aligned}
K=\left(2 . \pi \cdot 620[\mathrm{~mm}] \cdot \frac{340^{\circ}}{360^{\circ}}\right)+\left(2 . \pi \cdot 680[\mathrm{~mm}] \cdot \frac{302^{\circ}}{360^{\circ}}\right)+\left(2 . \pi \cdot 740[\mathrm{~mm}] \cdot \frac{302^{\circ}}{360^{\circ}}\right) \\
\quad+\left(2 . \pi \cdot 800[\mathrm{~mm}] \cdot \frac{322^{\circ}}{360^{\circ}}\right)
\end{aligned} \\
& K=15,666.10[\mathrm{~mm}]
\end{aligned}
$$

Luas penampang:

$$
A=\pi . d . L
$$




$$
\begin{aligned}
& A=\pi .40[\mathrm{~mm}] .15,666.10[\mathrm{~mm}] \\
& A=1,967,661.56[\mathrm{~mm} 2]=1.97[\mathrm{~m} 2]
\end{aligned}
$$

Dari hasil analisa turbine guide bearing cooling tube dilapangan, perhitungan luas penampang yang merupakan permukaan area kontak (surface area) atau yang biasa disebut permukaan utama (primary) didapatkan luas permukaan utama sebesar 1,967,661.56 $\left[\mathrm{mm}^{2}\right]=1.97\left[\mathrm{~m}^{2}\right]$, sehingga didapatkan:

dimana:

$$
N T U=\frac{U . A}{C_{\min }} \quad \text { (Ali H. Pane, Alat Penukar Kalor, 1.20) }
$$

$$
C_{\min }=\text { Kalor jenis terkecil yang digunakan }=C_{o i l}=1,450\left[\mathrm{~J} / \mathrm{kg}^{\circ} \mathrm{C}\right]
$$

maka :

$$
\begin{aligned}
& N T U=\frac{98.87\left[\mathrm{~W} / \mathrm{m}^{2}{ }^{\circ} \mathrm{C}\right] \cdot 1.97\left[\mathrm{~m}^{2}\right]}{1,450\left[\mathrm{~J} / \mathrm{kg}{ }^{\circ} \mathrm{C}\right]} \\
& N T U=0.13
\end{aligned}
$$

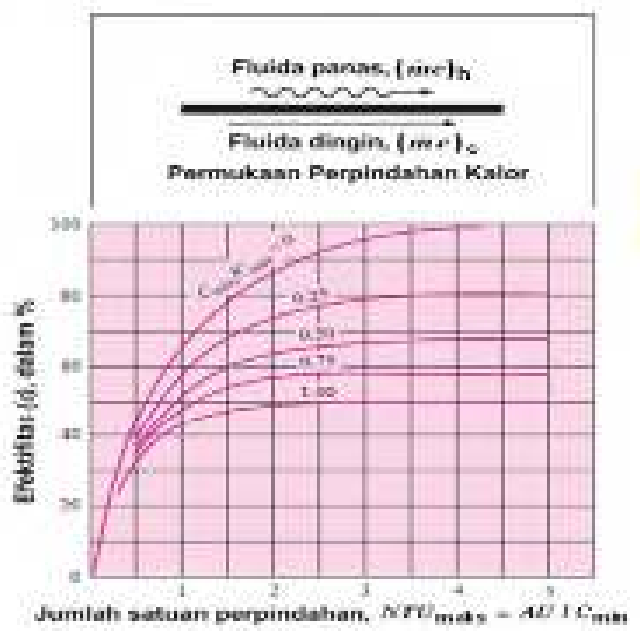

Gambar 8. Grafik Efektivitas Heat Exchanger aliran searah

Berdasarkan Gambar 8 Efektivitas Heat Exchanger aliran sejajar, dimana $C_{\min } / C_{\max }=0.35 \& N T U=0.13$, maka diperoleh efektivitas $=14 \%$.

Berdasarkan hasil pengambilan data temperatur air dan oli guide bearing cooling tube yang dilakukan di PLTA Siguragura Temperature Daily Report - Siguragura P.S.), temperatur inlet air dan oli sebesar $T c, i n=25.0\left[{ }^{\circ} \mathrm{C}\right] \& T h$, in $=47.3\left[{ }^{\circ} \mathrm{C}\right]$. Maka didapatkan laju perpindahan kalor maksimal yang memungkinkan dengan persamaan:

$$
Q_{\text {maks }}=C_{\text {min }} \cdot\left(T_{h, \text { in }}-T_{c, \text { in }}\right) \quad \text { (Ali H. Pane, Alat Penukar Kalor, 1.23) }
$$

dimana

maka,

$$
C_{\min }=\text { Kalor jenis terkecil yang digunakan }=\text { Coil }=1,450\left[\mathrm{~J} / \mathrm{kg}^{\circ} \mathrm{C}\right]
$$

$$
\begin{aligned}
Q_{\text {maks }} & =1,450\left[\mathrm{~J} / \mathrm{kg}^{\circ} \mathrm{C}\right] \cdot\left(47.3\left[{ }^{\circ} \mathrm{C}\right]-25.0\left[{ }^{\circ} \mathrm{C}\right]\right) \\
Q_{\text {maks }} & =32,335[\mathrm{~W}]
\end{aligned}
$$

Persamaan efektivitas digunakan untuk menentukan laju perpindahan kalor aktual, sebagai berikut: 


$$
\begin{aligned}
\varepsilon & =\frac{Q_{\text {aktual }}}{Q_{\text {maks }}} \\
14[\%] & =\frac{Q_{\text {aktual }}}{32,335[\mathrm{~W}]} \quad \text { (Ali H. Pane, Alat Penukar Kalor, }
\end{aligned}
$$

Hasil perhitungan laju perpindahan kalor digunakan untuk menentukan temperatur yang dapat dicapai dengan formula sebagai berikut :

$$
Q=\dot{\mathrm{m}} \cdot C_{p} \cdot\left(T_{c, \text { out }}-T_{c, \text { in }}\right)_{\text {air }} \quad \text { (Ali H. Pane, Alat Penukar Kalor) }
$$

Keterangan :

Sehingga,

$$
\begin{aligned}
& Q=\text { Laju perpindahan kalor }[\mathrm{W}] \dot{\mathrm{m}}=\text { Laju aliran masa }[\mathrm{kg} / \mathrm{s}] C_{p} \\
& \quad=\text { Kalor jenis fluida }=\text { Cwater }=4,180\left[\mathrm{~J} / \mathrm{kg}{ }^{\circ} \mathrm{C}\right] T_{c, \text { in }} \\
& \quad=\text { Temperatur air saat masuk }\left[{ }^{\circ} \mathrm{C}\right] T_{c, \text { out }}=\text { Temperatur air saat keluar }\left[{ }^{\circ} \mathrm{C}\right]
\end{aligned}
$$

$$
\begin{aligned}
& 4,203.55[\mathrm{~W}] 0.65[\mathrm{~kg} / \mathrm{s}] \cdot 4,180\left[\mathrm{~J} / \mathrm{kg}^{\circ} \mathrm{C}\right] \cdot\left(T_{c, \text { out }}-25.0\left[{ }^{\circ} \mathrm{C}\right]\right) \\
& T_{c, \text { out }}=26.54\left[{ }^{\circ} \mathrm{C}\right]
\end{aligned}
$$

Sedangkan perhitungan untuk menentukan temperatur oli dengan formula sebagai berikut:

$Q=\dot{\mathrm{m}} \cdot C_{p} \cdot\left(T_{h, \text { in }}-T_{h, \text { out }}\right)_{\text {oli }}$ (Ali H. Pane, Alat Penukar Kalor)

$Q=\dot{\mathrm{m}} \cdot C_{p} \cdot\left(T_{h, \text { in }}-T_{h, \text { out }}\right)_{\text {oli }}$ (Ali H. Pane, Alat Penukar Kalor, 1.3)

Sehingga,

$$
\begin{aligned}
& 4,203.55[\mathrm{~W}]=0.65[\mathrm{~kg} / \mathrm{s}] \cdot 1,450\left[\mathrm{~J} / \mathrm{kg}{ }^{\circ} \mathrm{C}\right] \cdot\left(47.3\left[{ }^{\circ} \mathrm{C}\right]-T_{h, \text { out }}\right) \\
& T_{h, \text { out }}=42.85\left[{ }^{\circ} \mathrm{C}\right]
\end{aligned}
$$

\subsection{Analisa Guide Bearing Cooling Tube 2 Layer}

Sementara pada guide bearing cooling tube dengan 2 layer merupakan yang terpasang saat ini di PLTA Siguragura dengan bentuk sebagai berkut :

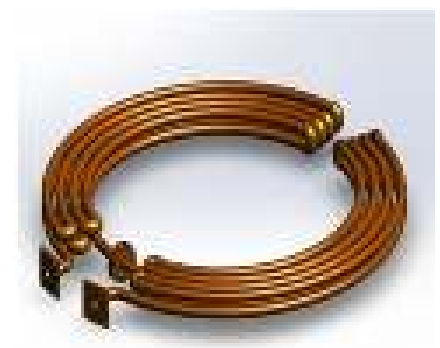

Gambar 9. Guide bearing cooling tube

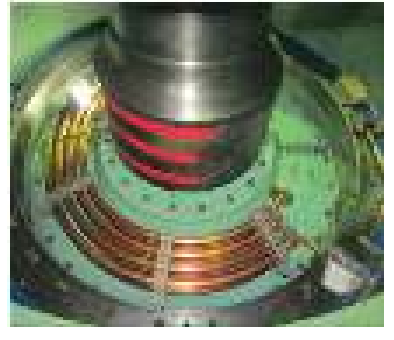

(a)

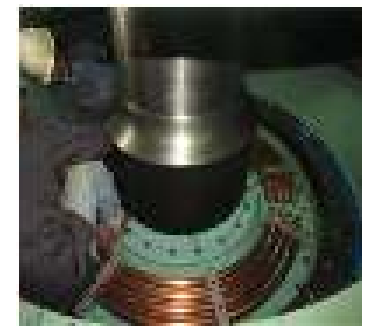

(b)

Gambar 10. (a) Proses pemasangan (b) pengukuran dimensi guide bearing cooling tube 
Dari hasil pengukuran pada saat pemasangan guide bearing cooling tube dilapangan, didapatkan dimensi yang digunakan untuk perhitungan luas penampang yang merupakan permukaan area kontak (surface area) atau yang biasa disebut permukaan utama (primary)dengan luas hasil perhitungan sebagai berikut :

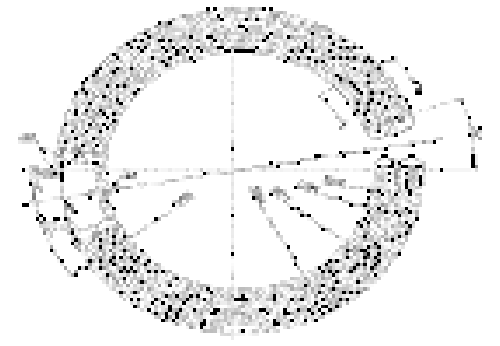

Gambar 11. Detail drawing Turbine Guide Bearing Cooling Tube

Tabel 5. Dimensi Layer Guide Bearing Cooling Tube

\begin{tabular}{|l|c|c|}
\hline \multicolumn{3}{|c|}{ Upper Layer Guide Bearing Cooling Tube } \\
\hline \multicolumn{1}{|c|}{ Item Pengukuran } & Dimensi Jari-jari [mm] & Sudut Keliling [ $\left.{ }^{\circ}\right]$ \\
\hline Jari-jari 1 (R1) & $620[\mathrm{~mm}]$ & $302\left[^{\circ}\right]$ \\
\hline Jari-jari 2 (R2) & $680[\mathrm{~mm}]$ & $302\left[^{\circ}\right]$ \\
\hline Jari-jari 3 (R3) & $740[\mathrm{~mm}]$ & $302\left[^{\circ}\right]$ \\
\hline Jari-jari 4 (R4) & $800[\mathrm{~mm}]$ & $302\left[^{\circ}\right]$ \\
\hline Jari-jari 1 (R1') & $620[\mathrm{~mm}]$ & $340\left[^{\circ}\right]$ \\
\hline Jari-jari 2 (R2') & $680[\mathrm{~mm}]$ & $302\left[^{\circ}\right]$ \\
\hline Jari-jari 3 (R3') & $740[\mathrm{~mm}]$ & $302\left[^{\circ}\right]$ \\
\hline Jari-jari 4 (R4') & $800[\mathrm{~mm}]$ & $322\left[^{\circ}\right]$ \\
\hline
\end{tabular}

$$
K=2 \cdot \pi \cdot r \cdot \frac{x}{360^{\circ}}
$$

Panjang bentangan

$$
\begin{aligned}
K=\left(2 . \pi .620[\mathrm{~mm}] \cdot \frac{302^{\circ}}{360^{\circ}}\right)+\left(2 . \pi .680[\mathrm{~mm}] \cdot \frac{302^{\circ}}{360^{\circ}}\right)+\left(2 . \pi .740[\mathrm{~mm}] \cdot \frac{302^{\circ}}{360^{\circ}}\right) \\
+\left(2 . \pi .800[\mathrm{~mm}] \cdot \frac{302^{\circ}}{360^{\circ}}\right)+\left(2 . \pi .620[\mathrm{~mm}] \cdot \frac{340^{\circ}}{360^{\circ}}\right) \\
+\left(2 . \pi .680[\mathrm{~mm}] \cdot \frac{302^{\circ}}{360^{\circ}}\right)+\left(2 . \pi .740[\mathrm{~mm}] \cdot \frac{302^{\circ}}{360^{\circ}}\right) \\
+\left(2 . \pi .800[\mathrm{~mm}] \cdot \frac{322^{\circ}}{360^{\circ}}\right) \\
K=30,641.46[\mathrm{~mm}]
\end{aligned}
$$

Luas permukaan guide bearing cooling tube:

$$
\begin{aligned}
& A=\pi . L . d \\
& A=\pi .40[\mathrm{~mm}] \cdot 30,641.46[\mathrm{~mm}] \\
& A=3,850,519.42\left[\mathrm{~mm}^{2}\right]=3.85\left[\mathrm{~m}^{2}\right]
\end{aligned}
$$

Dari hasil pengukuran pada saat pemasangan turbine guide bearing cooling tube dilapangan, perhitungan luas penampang yang merupakan permukaan area kontak (surface area) atau yang biasa disebut permukaan utama(primary) didapatkan luas permukaan utama $3,850,519.42\left[\mathrm{~mm}^{2}\right]=3.85\left[\mathrm{~m}^{2}\right]$. 
Berdasarkan hasil pengambilan data temperatur air dan oli guide bearing cooling tube yang dilakukan di PLTA Siguragura Unit No. 2 didapatkan data seperti berikut:

Tabel 6. Temperatur air dan oli pada PLTA Siguragura Unit No. 2

\begin{tabular}{|c|l|r|}
\hline \multicolumn{1}{|c|}{ Item } & \multicolumn{1}{|c|}{ Description } & \multicolumn{1}{c|}{ Temperature } \\
\hline \multirow{2}{*}{ Guide Bearing Cooling Tube } & W/T G. Metal (Inlet) $($ T1) & $47.3\left[{ }^{\circ} \mathrm{C}\right]$ \\
\cline { 2 - 3 } & W/T G. Oil (Outlet) $(T 2)$ & $\mathbf{4 1 . 6}\left[{ }^{\circ} \mathbf{C}\right]$ \\
\hline \multirow{2}{*}{ Cooling Water System } & Inlet (T3) & $25.0\left[{ }^{\circ} \mathrm{C}\right]$ \\
\cline { 2 - 3 } & Outlet (T4) & $\mathbf{2 7 . 5}\left[{ }^{\circ} \mathbf{C}\right]$ \\
\hline \multirow{2}{*}{ Ambient Temperatur } & Turbine Pit & $28.0\left[{ }^{\circ} \mathrm{C}\right]$ \\
\cline { 2 - 3 } & Generator Room & $27.5\left[{ }^{\circ} \mathrm{C}\right]$ \\
\hline
\end{tabular}

\subsection{Analisa Guide Bearing Cooling Tube 3 Layer}

Pada desain yang direncanakan berikutnya, turbine guide bearing cooling tube akan dianalisa menjadi 3 layer. Pada turbine guide bearing coling tube ini akan direncanakan pernambahan panjang dan dianalisa perubahan temperatur yang dapat dicapai dengan turbine guide bearing cooling tube 3 layer tersebut. Rancangan turbine guide bearing cooling tube 3 layer sebagai berikut :

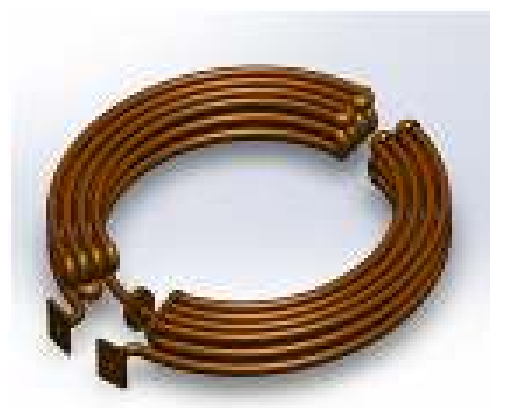

Gambar 12. Guide bearing cooling tube 3 layer

Dari hasil perhitungan pada rencana perancangan turbine guide bearing cooling tube yang dimodifikasi, didapatkan dimensi yang lebih panjang dari turbine guide bearing cooling tube dengan 1 layer atau 2 layerdigunakan untuk perhitungan luas penampang yang merupakan permukaan area kontak (surface area)atau biasa disebut permukaan utama (primary surface) dengan perhitungan dimnesi atau luas penampang sebagai berikut :

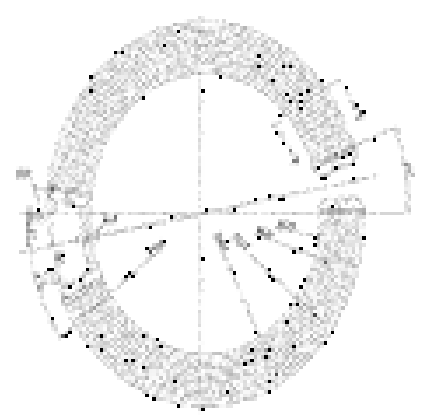

Gambar 13. Detail drawing Turbine Guide Bearing Cooling Tube 3 layer 
Tabel 7. Dimensi 3 Layer Guide Bearing Cooling Tube

\begin{tabular}{|c|c|c|}
\hline \multicolumn{3}{|c|}{ Lower Layer Guide Bearing Cooling Tube } \\
\hline Item Pengukuran & Dimensi Jari-jari [mm] & $\begin{array}{c}\text { Sudut Keliling } \\
{\left[{ }^{\circ}\right]}\end{array}$ \\
\hline Jari-jari $1(\mathrm{R} 1)$ & $620[\mathrm{~mm}]$ & $340\left[^{\circ}\right]$ \\
\hline Jari-jari 2 (R2) & $680[\mathrm{~mm}]$ & $302\left[^{\circ}\right]$ \\
\hline Jari-jari 3 (R3) & $740[\mathrm{~mm}]$ & $302\left[^{\circ}\right]$ \\
\hline Jari-jari 4 (R4) & $800[\mathrm{~mm}]$ & $322\left[^{\circ}\right]$ \\
\hline Jari-jari 1 (R1') & $620[\mathrm{~mm}]$ & $302\left[^{\circ}\right]$ \\
\hline Jari-jari 2 (R2') & $680[\mathrm{~mm}]$ & $302\left[^{\circ}\right]$ \\
\hline Jari-jari 3 (R3') & $740[\mathrm{~mm}]$ & $302\left[^{\circ}\right]$ \\
\hline Jari-jari 4 (R4') & $800[\mathrm{~mm}]$ & $302\left[^{\circ}\right]$ \\
\hline Jari-jari 1 (R1'’) & $620[\mathrm{~mm}]$ & $302\left[^{\circ}\right]$ \\
\hline Jari-jari 2 (R2'’) & $680[\mathrm{~mm}]$ & $302\left[^{\circ}\right]$ \\
\hline Jari-jari 3 (R3'’) & $740[\mathrm{~mm}]$ & $302\left[^{\circ}\right]$ \\
\hline Jari-jari 4 (R4'’) & $800[\mathrm{~mm}]$ & $302\left[^{\circ}\right]$ \\
\hline
\end{tabular}

$$
K=2 \cdot \pi \cdot r \cdot \frac{x}{360^{\circ}}
$$

Panjang bentangan guide bearing cooling tube:

$$
\begin{aligned}
K=\left(2 . \pi .620[\mathrm{~mm}] \cdot \frac{302^{\circ}}{360^{\circ}}\right)+\left(2 . \pi \cdot 680[\mathrm{~mm}] \cdot \frac{302^{\circ}}{360^{\circ}}\right)+\left(2 . \pi .740[\mathrm{~mm}] \cdot \frac{302^{\circ}}{360^{\circ}}\right) \\
+\left(2 . \pi .800[\mathrm{~mm}] \cdot \frac{302^{\circ}}{360^{\circ}}\right)+\left(2 . \pi .620[\mathrm{~mm}] \cdot \frac{340^{\circ}}{360^{\circ}}\right)+\left(2 . \pi .680[\mathrm{~mm}] \cdot \frac{302^{\circ}}{360^{\circ}}\right) \\
+\left(2 . \pi .740[\mathrm{~mm}] \cdot \frac{302^{\circ}}{360^{\circ}}\right)+\left(2 . \pi .800[\mathrm{~mm}] \cdot \frac{322^{\circ}}{360^{\circ}}\right)+\left(2 . \pi .620[\mathrm{~mm}] \cdot \frac{302^{\circ}}{360^{\circ}}\right) \\
+\left(2 . \pi .680[\mathrm{~mm}] \cdot \frac{302^{\circ}}{360^{\circ}}\right)+\left(2 . \pi .740[\mathrm{~mm}] \cdot \frac{302^{\circ}}{360^{\circ}}\right)+\left(2 . \pi .800[\mathrm{~mm}] \cdot \frac{302^{\circ}}{360^{\circ}}\right)
\end{aligned}
$$

$K=45,616.83[\mathrm{~mm}]$

Luas permukaan guide bearing cooling tube:

$$
\begin{aligned}
& A=\pi . L . d \\
& A=\pi .40[\mathrm{~mm}] .45,616.83[\mathrm{~mm}] \\
& A=5,729,473.27[\mathrm{~mm} 2]=5.73[\mathrm{~m} 2]
\end{aligned}
$$

Dari hasil analisa turbine guide bearing cooling tube dilapangan, perhitungan luas penampang yang merupakan permukaan area kontak (surface area) atau yang biasa disebut permukaan utama (primary) didapatkan luas permukaan utama sebesar 5,729,473.27 $\left[\mathrm{mm}^{2}\right] / 5.73\left[\mathrm{~m}^{2}\right]$, sehingga didapatkan :

dimana

$$
N T U=\frac{U . A}{C_{\min }} \quad \text { (Ali H. Pane, Alat Penukar Kalor), }
$$

sehingga :

$$
C_{\min }=\text { Kalor jenis terkecil yang digunakan }=\text { Coil }=1,450\left[\mathrm{~J} / \mathrm{kg}^{\circ} \mathrm{C}\right]
$$




$$
\begin{aligned}
& N T U=\frac{98.87\left[\mathrm{~W} / \mathrm{m}^{2 \circ} \mathrm{C}\right] \cdot 5.73\left[\mathrm{~m}^{2}\right]}{1,450\left[\mathrm{~J} / \mathrm{kg}^{\circ} \mathrm{C}\right]} \\
& N T U=0.39
\end{aligned}
$$

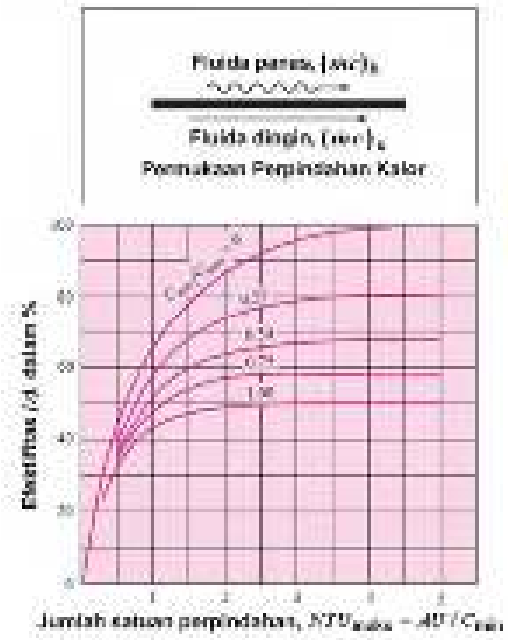

Gambar 14. Grafik Efektivitas Heat Exchanger aliran searah

Berdasarkan hasil pengambilan data temperatur air dan oli guide bearing cooling tube yang dilakukan di PLTA Siguragura Unit No. 2

Maka didapatkan laju perpindahan kalor maksimal yang memungkinkan dengan persamaan:

$$
\begin{aligned}
& Q_{\text {maks }}=C_{\min } \cdot\left(T_{h, \text { in }}-T_{c, \text { in }}\right) \quad(\text { Ali H. Pane, Alat Penukar Kalor, ) } \\
& Q_{\text {maks }}=1,450\left[\mathrm{~J} / \mathrm{kg}^{\circ} \mathrm{C}\right]\left(47.3\left[{ }^{\circ} \mathrm{C}\right]-25.0\left[{ }^{\circ} \mathrm{C}\right]\right) \\
& Q_{\text {maks }}=32,335[\mathrm{~W}]
\end{aligned}
$$

Persamaan efektivitas digunakan untuk menentukan laju perpindahan kalor aktual, sebagai berikut :

$$
\begin{aligned}
& \varepsilon=\frac{Q_{\text {aktual }}}{Q_{\text {maks }}} \quad \text { (Ali H. Pane, Alat Penukar Kalor, 1.20) } \\
& 34[\%]=\frac{Q_{\text {aktual }}}{32,335[\mathrm{~W}]} \\
& Q_{\text {aktual }}=10,933.9[\mathrm{~W}]
\end{aligned}
$$

Hasil perhitungan laju perpindahan kalor digunakan untuk menentukan btemperatur yang dapat dicapai dengan formula sebagai berikut:

$$
Q=\dot{\mathrm{m}} \cdot C_{p} \cdot\left(T_{c, \text { out }}-T_{c, \text { in }}\right)_{\text {air }} \quad \text { (Ali H. Pane, Alat Penukar Kalor, ) }
$$

dimana :

$$
C_{p}=\text { Kalor jenis fluida }=\text { Cwater }=4,180\left[\mathrm{~J} / \mathrm{kg}{ }^{\circ} \mathrm{C}\right]
$$

Sehingga,

$$
\begin{aligned}
& 10,933.9[\mathrm{~W}]=0.65[\mathrm{~kg} / \mathrm{s}] \cdot 4,180\left[\mathrm{~J} / \mathrm{kg}{ }^{\circ} \mathrm{C}\right] \cdot\left(T_{c, \text { out }}-25.0\left[{ }^{\circ} \mathrm{C}\right]\right) \\
& \boldsymbol{T}_{\boldsymbol{c}, \text { out }}=\mathbf{2 9 . 0 4}\left[{ }^{\circ} \mathrm{C}\right]
\end{aligned}
$$

Sedangkan perhitungan untuk menentukan temperatur oli dengan formula sebagai berikut :

$$
Q=\dot{\mathrm{m}} \cdot C_{p} \cdot\left(T_{h, \text { in }}-T_{h, \text { out }}\right)_{\text {oli }} \quad \text { (Ali H. Pane, Alat Penukar Kalor, 1.3) }
$$

$10,933.9\left[\mathrm{~W}=0.65[\mathrm{~kg} / \mathrm{s}] \cdot 1,450\left[\mathrm{~J} / \mathrm{kg}{ }^{\circ} \mathrm{C}\right] \cdot\left(47.3\left[{ }^{\circ} \mathrm{C}\right]-T_{h, \text { out }}\right)\right.$

$\boldsymbol{T}_{h, o u t}=35.66\left[{ }^{\circ} \mathrm{C}\right]$ 


\subsection{Pembahasan}

Dari hasil analisa yang dilakukan terhadap turbine guide bearing cooling tube dengan beberapa variasi dimensi (luas penampang) didapatkan data temperatur oli terendah mencapai nilai $35.66\left[{ }^{\circ} \mathrm{C}\right]$ dengan variasi pipa heat exchanger 3 layer atau luas penampang sebesar $5.73\left[\mathrm{~m}^{2}\right]$.

Tabel 8. Perhitungan dimensi dan temperatur pada guide bearing cooling tube

\begin{tabular}{|c|c|c|c|c|c|c|c|}
\hline \multirow[b]{2}{*}{$\begin{array}{l}\text { Gutde Bearing } \\
\text { Cooling Tube }\end{array}$} & \multirow[b]{2}{*}{$\begin{array}{l}\text { Luas } \\
{\left[\mathrm{m}^{2}\right]}\end{array}$} & \multicolumn{2}{|c|}{ Air } & \multicolumn{2}{|c|}{ Oli } & \multirow[b]{2}{*}{$\begin{array}{c}\Delta \mathrm{T} \max \\
\Gamma^{\circ} \mathrm{Cl}\end{array}$} & \multirow[b]{2}{*}{$\begin{array}{c}\Delta T_{m i n} \\
\left.\Gamma^{\circ} \mathrm{C}\right\rceil\end{array}$} \\
\hline & & $\begin{array}{l}T_{c}, \text { in } \\
\Gamma^{\circ} \mathrm{Cl}\end{array}$ & $\begin{array}{c}\text { To, out } \\
{ }^{\circ}{ }^{\circ} \mathrm{Cl}\end{array}$ & $\begin{array}{l}\text { Th, in } \\
1{ }^{\circ} \mathrm{Cl}\end{array}$ & $\begin{array}{c}\text { Th, out } \\
{ }^{\circ} \mathrm{Cl}\end{array}$ & & \\
\hline 1 Layer & 1.97 & 25.00 & 26.54 & 47.30 & 42.85 & 22.30 & 16.31 \\
\hline 2 Layer & 3.85 & 25.00 & 27.5 & 47.30 & 41.60 & 22.30 & 14.10 \\
\hline 3 Layer & 5.73 & 25.00 & 29.04 & 47.30 & 35.66 & 22.30 & 6.63 \\
\hline
\end{tabular}

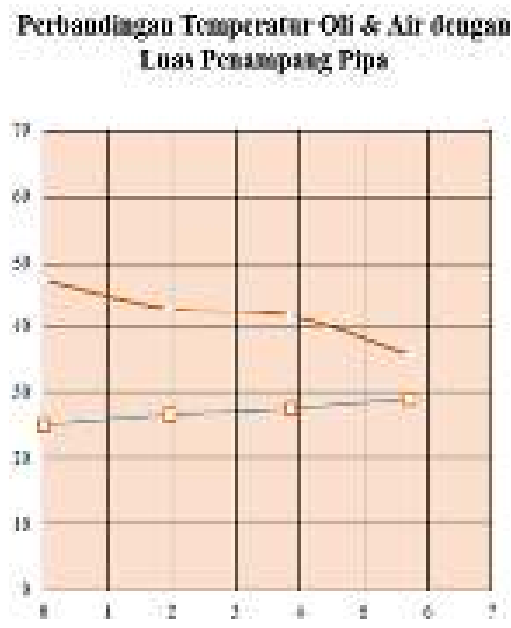

Gambar 15. Grafik Perbandingan Temperatur Oli \& Air dengan Luas Penampang Pipa

Pada Gambar 15 Grafik Perbandingan Temperatur Oli \& Air dengan Luas Penampang Pipa dijelaskan bahwa $\Delta T_{\min }$ yang dapat dicapai dengan luas penampang $5.73\left[\mathrm{~m}^{2}\right]$ adalah sebesar $6.63\left[{ }^{\circ} \mathrm{C}\right]$.

\section{KESIMPULAN}

Dari hasil pengambilan data, analisa perancangan, dan perhitungan yang sudah dilakukan pada turbine guide bearing cooling tube, maka dapat diambil kesimpulan :

a Temperatur maksimum pada guide bearing cooling tube mencapai $47.3\left[{ }^{\circ} \mathrm{C}\right]$.

b Pada guide bearing cooling tube terdapat perpindahan yang terjadi dengan cara perindahan kalor konduksi dan konveksi.

c Hasil perhitungan koefisien perpindahan kalor menyeluruh pada guide bearing cooling tube adalah $98.87\left[\mathrm{~W} / \mathrm{m}^{20} \mathrm{C}\right]$.

d $\Delta$ Tmin pada guide bearing cooling tube yang terpasang sekarang (dengan 2 layer) adalah $14.1\left[{ }^{\circ} \mathrm{C}\right]$. 
e $\Delta T \min$ yang dapat dicapai dengan luas penampang $5.73\left[\mathrm{~m}^{2}\right]$ adalah sebesar 6.63 $\left[{ }^{\circ} \mathrm{C}\right]$.

\section{DAFTAR PUSTAKA}

1. https://nurulimantmunib.wordpress.com/2011/08/14/sistem-thermodinamika/

2. 2010, Tarik Al-Shemmeri, Engineering Thermodynamics (First Edision), ISBN 97887-7681-670-4

3. http://www.sainsseru.com/2018/01/perpindahan-kalor-konduksi-konveksiradiasi.html

4. http://seputarpengertian.blogspot.com/201707/pengertian-perpindahan-kalorsecara-.html

5. http://sriwulandaritermodinamika.blogspot.com/2015/03/alat-penukar-kalor-heatexchanger.html

6. http://sriwulandaritermodinamika.blogspot.com/2015/03/alat-penukar-kalor-heatexchanger.html

7. https://artikel-teknologi.com/macam-macam-heat-exchanger-alat-penukar-panasbagian-5/

8. 2014, Ali Hasimi Pane, Alat Penukar Kalor (Heat Exchanger), Advance Learning Consultant

9. 1989, Roger Kinsky, Heat Engineering (An Introduction to Thermodinamics)

10. Agus, Nuniek Avianti. 2008. Mudah Belajar Matematika 3 Untuk Kelas IX Sekolah Menengah Pertama/Madrasah Tsanawiyah. Jakarta: Pusat Perbukuan, Departemen Pendidikan Nasional 